\title{
An Effective Method of Continuous Production of Erythritol from Glycerol by Yarrowia lipolytica MK1
}

\author{
Magdalena Rakicka*, Aleksandra M. Mirończuk, Ludwika Tomaszewska-Hetman, \\ Anita Rywińska and Waldemar Rymowicz \\ Department of Biotechnology and Food Microbiology, Wroclaw University of Environmental \\ and Life Sciences, Chełmońskiego St. 37, PL-51-630 Wroclaw, Poland
}

Received: June 3, 2016

Accepted: November 7, 2016

\begin{abstract}
Summary
This study demonstrates the potential applicability of the UV mutant Yarrowia lipolytica MK1 for the valorisation of glycerol and erythritol production in a chemostat culture. The aim of this research is to investigate the optimal C:N ratio in the feeding medium in order to enhance erythritol production. The highest erythritol concentration, at $113.1 \mathrm{~g} / \mathrm{L}$ with a volumetric erythritol production rate of $1.1 \mathrm{~g} /(\mathrm{L} \cdot \mathrm{h})$ and a yield of $0.57 \mathrm{~g} / \mathrm{g}$, was obtained in the feeding medium with a C:N ratio of 80:1. Moreover, no residual glycerol was observed in the culture broth during cultivation. The chemical composition of the biomass was analysed. The contents of lysine and threonine in the biomass protein amino acid profile were higher than those required by the FAO/WHO for fodder yeast.
\end{abstract}

Key words: erythritol, glycerol, chemostat, Yarrowia lipolytica

\section{Introduction}

Erythritol is a sugar alcohol from a group of polyols that occurs in nature as a metabolite or storage compound in seaweeds or fungi, as well as a component of fruits such as pears, melons and grapes (1). It has about $60-80 \%$ of the sweetness of sucrose in a $10 \%$ solution. Its taste profile resembles that of sucrose, and in many countries it has been safely used in food as a noncariogenic sweetener $(2,3)$. Erythritol is produced in microbiological processes from carbohydrates, especially from glucose, using osmophilic yeast such as Moniliella sp. (4), Trichosporon sp. (5), Aureobasidium sp. (6), Torula sp. (7) or Pseudozyma tsukubaensis (8). Moreover, erythritol may be produced at low $\mathrm{pH}$ values also from glycerol by the oleaginous yeast Yarrowia lipolytica $(9,10)$. Various factors affecting fermentation have been examined, e.g. different cultivation systems, type of substrate, and addition of salt or supplementation with minerals $(9,11-15)$. Up to now, the batch, fed-batch or repeated-batch cultures have been tested for erythritol biosynthesis from glycerol $(9,13)$. However, the application of a chemo- stat culture, which is a very promising cultivation system, especially for yeast known to produce well-dispersed, unicellular populations, has never been reported. Continuous cultivation with yeast is successfully used in biotechnology, e.g. in the production of biodiesel (16), bulk chemicals (17), xylitol (18) or citric acid (1).

The overall goal of this study is to improve the production of erythritol on glycerol media with the Y. lipolytica MK1 strain in the classic single-step continuous chemostat culture. The specific objective of this research is to investigate the optimal C:N ratio in the feeding medium in order to enhance erythritol production.

\section{Materials and Methods}

\section{Strain}

The Yarrowia lipolytica MK1 strain used in this study was isolated from the acetate-negative mutant strain $Y$. lipolytica Wratislavia K1 after its exposure to UV irradiation (19). 


\section{Media and culture conditions}

Pure glycerol (purity of $98 \%$; Avantor Performance Materials Poland S.A, Gliwice, Poland) was applied in the study. The growth medium for the inoculation culture contained (in g/L): pure glycerol 50, yeast extract 3, malt extract 3 and Bacto ${ }^{\mathrm{TM}}$ Peptone 5 (Sigma-Aldrich, St. Louis, MO, USA).

The chemostat culture was started as a batch culture in the nitrogen-limited medium that contained (in $\mathrm{g} / \mathrm{L}$ ): glycerol 100, $\left(\mathrm{NH}_{4}\right)_{2} \mathrm{SO}_{4} 2.3, \mathrm{KH}_{2} \mathrm{PO}_{4} 0.22, \mathrm{MgSO}_{4} \cdot 7 \mathrm{H}_{2} \mathrm{O}$ 1.0, yeast extract 1 and $\mathrm{NaCl} 26.5$ (12). After $24 \mathrm{~h}$ of batch culture the chemostat process was started at a dilution rate of $0.01 \mathrm{~h}^{-1}$. Three different feeding media were tested with various C:N ratios. Production medium 1 (PM1) with a C:N ratio of 160:1 (by mass) consisted of (in $\mathrm{g} / \mathrm{L}$ ): glycerol 200, $\left(\mathrm{NH}_{4}\right)_{2} \mathrm{SO}_{4} 2.3, \mathrm{KH}_{2} \mathrm{PO}_{4} 0.22, \mathrm{MgSO}_{4} \cdot 7 \mathrm{H}_{2} \mathrm{O}$ 1.0, yeast extract 1 and $\mathrm{NaCl} 26.5$. Production medium 2 (PM2) with a C:N ratio of 80:1 (by mass) contained (in $\mathrm{g} / \mathrm{L}$ ): glycerol 200, $\left(\mathrm{NH}_{4}\right)_{2} \mathrm{SO}_{4} 4.6$, and other components at the concentrations given above for PM1. Production medium 3 (PM3) with a C:N ratio of 80:1 (by mass) consisted of (in g/L): glycerol 300, $\left(\mathrm{NH}_{4}\right)_{2} \mathrm{SO}_{4} 6.9$, and other components as given above.

All cultures were made in a 5-litre stirred tank reactor (Biostat B plus; Sartorius, Göttingen, Germany). Each feeding medium was added to the bioreactor at a rate of 5.0 $\mathrm{mL} / \mathrm{h}$ and at the same time culture liquid was continuously removed at an equal rate to keep the working volume constant at $1.5 \mathrm{~L}$. The steady state of each culture was achieved after about $200 \mathrm{~h}$, when all culture parameters (specific growth rate, biomass and product concentrations, culture volume and dissolved oxygen concentration) remained constant. The residence time for the chemostat culture was $100 \mathrm{~h}$ and the processes were stable during $400 \mathrm{~h}$.

An inoculum of $0.2 \mathrm{~L}$ was added to the bioreactor containing $1.3 \mathrm{~L}$ of the medium. The stirring rate and aeration space velocity were $13.3 \mathrm{~Hz}$ and $0.6 \mathrm{~min}^{-1}$, respectively (20). The temperature was maintained at $30^{\circ} \mathrm{C}$ and the $\mathrm{pH}$ was kept at 3.0 by the addition of $20 \% \mathrm{NaOH}$. The bioreactor containing the specific medium (prepared with tap water) was sterilised in an autoclave at $121^{\circ} \mathrm{C}$ for 20 $\mathrm{min}$. All cultures were prepared in two biological replicates and standard deviations were calculated.

\section{Analytical methods}

For dry biomass quantification $10 \mathrm{~mL}$ of culture broth were centrifuged (centrifuge model 5804/5804 R; Eppendorf, Hamburg, Germany) at 2700 $\times g$ for $5 \mathrm{~min}$. The biomass was washed with distilled water, filtered through a membrane with a pore size of $0.45 \mu \mathrm{m}$ and determined gravimetrically after drying at $105^{\circ} \mathrm{C}$, expressed in grams of cell dry mass per litre.

The total intracellular lipids were determined by the Soxhlet method (21). Fat was extracted using a Büchi B-811 universal extraction system (Büchi Labortechnic AG, Flawil, Switzerland). The fatty acid profile was determined in the fat extracted from yeast biomass according to the method described by Ackman (22) with some modifications: $0.2 \mathrm{~g}$ of dry biomass was treated with a mixture of $1 \mathrm{~mL}$ of benzene and $1 \mathrm{~mL}$ of $\mathrm{BF}_{3}$-methanol (Sigma-Aldrich). Next, the sample was shaken at $140 \mathrm{rpm}$ for 5 min, heated for $15 \mathrm{~min}$ at $50^{\circ} \mathrm{C}$ and cooled. After the addition of $0.5 \mathrm{~mL}$ of $\mathrm{H}_{2} \mathrm{O}$ the sample was centrifuged at $2700 \times g$ for $5 \mathrm{~min}$ and the upper layer was evaporated in a nitrogen atmosphere. Dry residue was dissolved in 0.1 $\mathrm{mL}$ of $\mathrm{CH}_{2} \mathrm{Cl}_{2}$ (Sigma-Aldrich). Fatty acid methyl esters were separated by gas chromatography (Philips, Cambridge, UK) according to the methodology described by Kita et al. (23).

The concentrations of glycerol, erythritol, mannitol, arabitol, citric acid and $\alpha$-ketoglutaric acid were measured in the culture supernatants by high-performance liquid chromatograph (Thermo Scientific, Waltham, MA, USA) using an HyperRez Carbohydrate H+ column (Thermo Scientific) coupled to a UV detector ( $\lambda=210 \mathrm{~nm}$; Dionex, Sunnyvale, CA, USA) and a refractive index detector (Shodex, Ogimachi, Japan). The column was eluted with $25 \mathrm{mM}$ trifluoroacetic acid at $65^{\circ} \mathrm{C}$ and a flow rate of $0.6 \mathrm{~mL} / \mathrm{min}$.

Protein concentration in the biomass harvested at the end of the cultivation was analysed using the Kjeldahl method (24). The amino acid profile was determined using an AAA400 Automatic Amino Acids Analyser (INGOS Ltd., Prague, Czech Republic).

\section{Results and Discussion}

\section{Effect of C: $N$ ratio on the growth and erythritol production by $Y$. lipolytica MK1 in a chemostat culture}

Continuous cultures undoubtedly have many advantages, among which the most important include the possibility to set the physiological state of the cells by selecting the flow rate of the feeding medium and the composition of the culture medium, physical and chemical homogeneity of the culture, automation of the process, higher process efficiency, maximisation of apparatus utilisation, and even spread of the workload $(25,26)$. However, the disadvantages of these processes are the difficulty in ensuring aseptic conditions and the possibility of degeneration or mutation of strains $(27,28)$. Some of the well-described continuous processes using $Y$. lipolytica yeast include the production of lipids from molasses and glycerol-containing medium (29) and the production of citric acid using glycerol as a carbon source (1). In the literature, there is a lack of information about erythritol production using chemostat cultivation.

In this study, three medium compositions were tested. The PM1 and PM2 had a C:N ratio of 160:1 and 80:1, respectively. The PM3 also had the C:N ratio of $80: 1$, but in this case the increased carbon and nitrogen concentrations were tested. Fig. 1a shows the influence of time and different medium composition on biomass production in chemostat cultures. All tested cultures were carried out for about $600 \mathrm{~h}$ and the steady state was achieved after about $200 \mathrm{~h}$ of cultivation, which is equal to almost five replacements of the culture medium in the bioreactor under steady state. The biomass concentration under steady state was the highest $(24.3 \mathrm{~g} / \mathrm{L})$ in the culture with PM3 where the C:N ratio of 80:1 and high ammonium sulfate concentration were applied (Fig. 1a). The lower content of 
nitrogen in the PM2 with the same C:N ratio resulted in lower biomass production (21.8 g/L) (Fig. 1a). In PM1, biomass concentration under steady state reached 11.6 g/L (Fig. 1a).

Figs. $1 \mathrm{~b}$ and $\mathrm{c}$ show the time courses of erythritol production and glycerol utilisation, respectively. Additionally, Table 1 summarises the parameters of erythritol production. High concentrations of erythritol were observed when PM2 and PM3 were applied, i.e. 113.1 and $112.6 \mathrm{~g} / \mathrm{L}$, respectively (Fig. 1b; Table 1). However, the highest productivity $(1.1 \mathrm{~g} /(\mathrm{L} \cdot \mathrm{h}))$ and erythritol production yield $(0.57 \mathrm{~g} / \mathrm{g})$ were observed in the PM2 culture (Table 1$)$. The increased concentration of carbon and nitrogen in PM3 without changes in the C:N ratio (80:1) did not improve productivity and yield of erythritol formation when compared to the PM2 (80:1) (Table 1). The application of the PM1 with the highest C:N ratio resulted in a significantly lower concentration of erythritol produced (83 g/L) (Fig. $1 b$, Table 1$)$, and its production parameters were also not satisfactory (Table 1).

Interestingly, there was a significant effect on a residual glycerol level when the $\mathrm{C}: \mathrm{N}$ ratio was changed from 160:1 to 80:1 (Fig. 1c). The residual glycerol concentration was the lowest in the PM2 culture and reached only about $1.9 \mathrm{~g} / \mathrm{L}$ under steady state (Fig. 1c). Its comparable concentration $(45 \mathrm{~g} / \mathrm{L})$ was observed in the chemostat PM1 and PM3 cultures (Fig. 1c), which indicates cost-ineffectiveness of the process and great loss of the substrate.

Batch or fed-batch cultures on glycerol are commonly used as systems for erythritol production, and therefore glycerol seems to be an efficient substrate for this purpose $(9,14)$. As reported before, in batch culture the same strain, Y. lipolytica MK1, was able to produce up to 82.2 $\mathrm{g} / \mathrm{L}$ of erythritol from glycerol with yield of $0.55 \mathrm{~g} / \mathrm{g}$ and productivity of $0.84 \mathrm{~g} /(\mathrm{L} \cdot \mathrm{h})(19)$. Erythritol production parameters obtained in this study in continuous cultivation were higher than those observed by Rywińska et al. (11) in a batch culture on crude glycerol using the parental strain Y. lipolytica Wratislavia K1. The application of crude glycerol at $13.3 \mathrm{~Hz}$ and $0.6 \mathrm{~min}^{-1}$ resulted in erythritol concentration of $58.2 \mathrm{~g} / \mathrm{L}$, yield of $0.38 \mathrm{~g} / \mathrm{g}$ and productivity of $0.78 \mathrm{~g} /(\mathrm{L} \cdot \mathrm{h})$. On the other hand, Rymowicz et al. (9) reported that in the fed-batch cultivation the application of crude glycerol (300 g/L) with Y. lipolytica Wratislavia K1 resulted in a higher concentration of erythritol $(170 \mathrm{~g} / \mathrm{L})$ with the same yield of erythritol production of $0.56 \mathrm{~g} / \mathrm{g}$ and lower productivity of $1.0 \mathrm{~g} /(\mathrm{L} \cdot \mathrm{h})$ than in the present study. Better results were obtained by Tomaszewska et al. (13) when using the parental strain Y. lipolytica Wratisla-
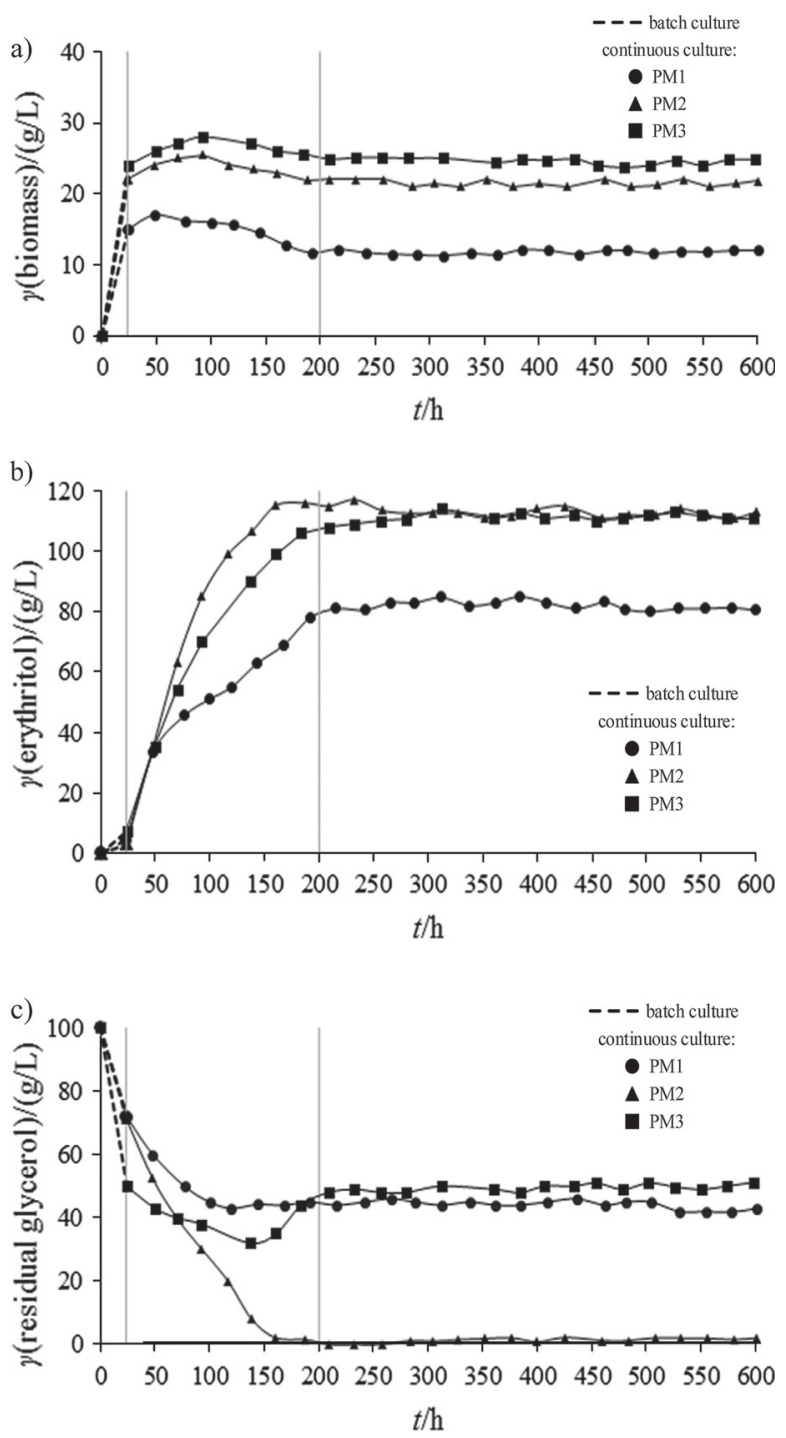

Fig. 1. Concentration of: a) biomass, b) erythritol, and c) residual glycerol during chemostat culture of Yarrowia lipolytica MK1 with glycerol and different $\mathrm{C}: \mathrm{N}$ ratios in the feeding medium (g/L). PM1, PM2 and PM3=production medium 1, 2 and 3 respectively

via $\mathrm{K} 1$ in the fed-batch system with pulsed addition of glycerol (325 g/L). Under these conditions, the yeast produced $201.2 \mathrm{~g} / \mathrm{L}$ of erythritol after $168 \mathrm{~h}$ of cultivation, which corresponded to a yield of $0.62 \mathrm{~g} / \mathrm{g}$ and productivity of $1.2 \mathrm{~g} /(\mathrm{L} \cdot \mathrm{h})(13)$.

Table 1. Parameters of erythritol production by Yarrowia lipolytica MK1 in a chemostat culture in media with different composition

\begin{tabular}{|c|c|c|c|c|c|c|c|c|c|c|}
\hline 蘉 & C:N & $\gamma$ (biomass) & $\gamma$ (erythritol) & $\gamma($ arabitol $)$ & $\gamma($ mannitol $)$ & $\begin{array}{c}\gamma(\text { citric } \\
\text { acid })\end{array}$ & $\begin{array}{c}\gamma(\alpha \text {-ketoglutaric } \\
\text { acid })\end{array}$ & $Q^{a}$ & $Y^{b}$ & $w\left(\right.$ protein $^{c}$ \\
\hline$\sum$ & & $\mathrm{g} / \mathrm{L}$ & $\mathrm{g} / \mathrm{L}$ & $\mathrm{g} / \mathrm{L}$ & $\mathrm{g} / \mathrm{L}$ & $\mathrm{g} / \mathrm{L}$ & $\mathrm{g} / \mathrm{L}$ & $g /(L \cdot h)$ & $\mathrm{g} / \mathrm{g}$ & $\%$ \\
\hline PM1 & 160:1 & $11.6 \pm 0.7$ & $83.0 \pm 3.2$ & $0.3 \pm 0.2$ & $1.9 \pm 0.6$ & $1.9 \pm 0.7$ & $0.5 \pm 0.2$ & $0.9 \pm 0.1$ & $0.42 \pm 0.02$ & $25.4 \pm 1.2$ \\
\hline PM2 & $80: 1$ & $21.8 \pm 0.8$ & $113.1 \pm 1.5$ & $0.3 \pm 0.2$ & $0.8 \pm 0.1$ & $1.4 \pm 1.1$ & $0.2 \pm 0.1$ & $1.1 \pm 0.2$ & $0.57 \pm 0.01$ & $29.5 \pm 1.9$ \\
\hline PM3 & $80: 1$ & $24.3 \pm 1.2$ & $112.6 \pm 2.7$ & $4.4 \pm 0.9$ & $1.6 \pm 1.0$ & $0.3 \pm 0.1$ & $0.4 \pm 0.2$ & $1.2 \pm 0.2$ & $0.38 \pm 0.01$ & $33.7 \pm 2.3$ \\
\hline
\end{tabular}

a average volumetric erythritol production rate under steady state, baverage erythritol production yield under steady state, 'amino acid composition is given in Table 2 
It is worth noting that erythritol has been produced commercially from glucose (3). The available data obtained when using different microorganisms on glucose media showed that the highest value of erythritol productivity in the fed-batch culture was $2.86 \mathrm{~g} /(\mathrm{L} \cdot \mathrm{h})$ with Pseudozyma tsukubaensis (8), whereas the highest value of erythritol production yield, $0.63 \mathrm{~g} / \mathrm{g}$, was noted by Lin et al. (4) with Moniliella sp. N61188-12, when compared to the present results. Similar productivity $(1.2 \mathrm{~g} /(\mathrm{L} \cdot \mathrm{h}))$ was obtained by Kohl et al. (30), who used Candida magnoliae in fed-batch fermentation with simultaneous glucose and yeast extract feeding. However, another mutant of Candida magnoliae in the medium with $20 \%$ glucose produced erythritol with lower productivity $(0.54 \mathrm{~g} /(\mathrm{L} \cdot \mathrm{h}))$ and yield $(0.43 \mathrm{~g} / \mathrm{g})$ than in this study $(26)$.

The high osmotic pressure caused by salt addition to the medium and a high concentration of glycerol are the key factors that enhance erythritol production by $Y$. lipolytica and at the same time reduce the formation of mannitol and arabitol $(31,32)$. In all tested chemostat cultures, regardless of $\mathrm{C}: \mathrm{N}$ ratio, the concentration of mannitol was low and did not exceed $2 \mathrm{~g} / \mathrm{L}$ (Table 1 ). Moreover, the concentration of arabitol remained at a very low level $(0.3$ g/L) when PM1 and PM2 where used. Arabitol concentration increased to $4.4 \mathrm{~g} / \mathrm{L}$ in PM3 (Table 1). Organic acids, such as citric and $\alpha$-ketoglutaric acids, were also determined in the culture broths, although in small quantities (Table 1). It is worth noting that selectivity of erythritol biosynthesis in all performed chemostat cultures was very satisfactory.

One limiting factor of chemostat culture is dissolved oxygen concentration (29). During chemostat cultures with PM2 and PM3 the dissolved oxygen concentration was lower than in PM1 and was about $20 \%$ in PM2 and PM3 and $45 \%$ in PM1 (data not shown). Low dissolved oxygen concentrations have been shown to induce the yeast-to-mycelium transition in Y. lipolytica. Bellou et al. (33) demonstrated that mycelial and pseudomycelial forms predominated over the yeast form when the dissolved oxygen concentration was low, regardless of the carbon and nitrogen sources used.

\section{The nutritional value of Y. lipolytica MK1 biomass}

For more in-depth investigation of the long-term chemostat culture, at the end of the cultivation the protein content of Y. lipolytica MK1 biomass was analysed (Table 1). The European Feed Manufacturers' Federation authorised the sale of $Y$. lipolytica fodder yeast produced from glycerol and registered it under catalogue number 00 575-EN (19). Therefore, the biomass from the chemostat culture was collected and nutritional characteristics were analysed for potential use as feed. The highest mass fraction of protein in the biomass reached $33.7 \%$ (Table 1) and was observed in the PM3, which also gave the highest biomass concentration (Fig. 1a). Yeast biomass that contains below $65 \%$ protein is referred to as single-cell biomass. Protein content of the biomass recommended for fodder yeasts in the standards established by the FAO/ WHO is $40-52 \%$ (34). Protein content in the culture with the PM2 was also high and reached $29.5 \%$. In comparison with the present work, a similar protein mass fraction ((35.2-36.5) \%) was noted by Juszczyk and Rymowicz (35) in the Y. lipolytica biomass produced using glycerol waste.
For comparison, the mass fraction of protein in the Y. lipolytica Wratislavia K1 biomass after the erythritol biosynthesis on pure glycerol in repeated-batch culture was lower and reached $16.9-23.4 \%$ when $40 \%$ of medium was replaced (19).

The PM2 gave the highest erythritol concentration, productivity and yield, with a low concentration of residual glycerol and by-products. Therefore, the biomass from the chemostat culture produced with the PM2 medium was also tested for amino acid, lipid, essential saturated and unsaturated fatty acid content. The amino acid composition in yeast biomass is strongly dependent on the yeast strain, medium composition, growth phase and cultivation time $(25,35)$. The amino acid profile showed that aspartic and glutamic acids were the main components of the proteins, constituting 11.6 and $11.3 \%$, respectively (Table 2). The other amino acids were identified as leucine, lysine, valine, alanine and threonine, in mass fractions of $10.5,8.7,8.0,8.0$ and $7.4 \%$, respectively. In contrast, the biomass of $Y$. lipolytica derived from the culture on raw glycerol was rich in lysine (8.26 g per $100 \mathrm{~g}$ of protein) and threonine (5.39 g per $100 \mathrm{~g}$ of protein) (34). Moreover, proteins in the Y. lipolytica MK1 biomass were poor in sulphuric amino acids (methionine and cysteine), which was also observed when other strains of Y. lipolytica were cultivated on pure as well as on raw glycerol $(34,35)$.

Table 2. Mass fractions of amino acids in Yarrowia lipolytica MK1 biomass derived from a chemostat culture with PM2 and C:N ratio of $80: 1$

\begin{tabular}{cc}
\hline Amino acid & $w /(\mathrm{g}$ per $100 \mathrm{~g}$ of protein $)$ \\
\hline Aspartic acid & 11.6 \\
Threonine & 7.4 \\
Serine & 6.5 \\
Glutamic acid & 11.3 \\
Proline & 6.1 \\
Alanine & 8.0 \\
Cysteine & 0 \\
Methionine & 1.8 \\
Valine & 8.0 \\
Isoleucine & 5.6 \\
Leucine & 10.5 \\
Tyrosine & 4.2 \\
Phenylalanine & 4.8 \\
Histidine & 2.5 \\
Lysine & 8.7 \\
Arginine & 5.4 \\
\hline
\end{tabular}

Culture conditions (in g/L): glycerol 200, $\left(\mathrm{NH}_{4}\right)_{2} \mathrm{SO}_{4} 4.6, \mathrm{KH}_{2} \mathrm{PO}_{4}$ $0.22, \mathrm{MgSO}_{4} \cdot 7 \mathrm{H}_{2} \mathrm{O} 1$, yeast extract 1 and $\mathrm{NaCl} 26.5$

The lipid content and the mass fractions of saturated, monounsaturated and polyunsaturated fatty acids in the Y. lipolytica MK1 biomass were analysed. Lipid content in the biomass was $20.9 \%$ (Table 3 ). The main fatty acid in the yeast biomass was oleic acid (C18:1n9; $38.2 \%)$, as observed when using other oleaginous yeasts $(31,32)$. Oleic acid was described as the main monounsaturated fatty 
Table 3. Mass fractions of saturated and unsaturated essential fatty acids in Yarrowia lipolytica MK1 biomass derived from a chemostat culture with PM2 and C:N ratio of $80: 1$

\begin{tabular}{cc}
\hline Fatty acid & $\begin{array}{c}w / \% \\
\text { in total fatty acids }\end{array}$ \\
\hline C16:0 & 19.0 \\
C18:0 & 10.3 \\
C16:1n7 $18: 1 n 9$ & 6.2 \\
C18:2n6 & 38.2 \\
C18:3n3 & 17.5 \\
$w$ (biomass lipids) & 0.2 \\
\hline
\end{tabular}

Culture conditions (in g/L): glycerol 200, $\left(\mathrm{NH}_{4}\right)_{2} \mathrm{SO}_{4} 4.6, \mathrm{KH}_{2} \mathrm{PO}_{4}$ $0.22, \mathrm{MgSO}_{4} \cdot 7 \mathrm{H}_{2} \mathrm{O} 1$, yeast extract $1, \mathrm{NaCl} 26.5$

acid in Y. lipolytica yeast biomass $(31,32)$, which was confirmed in the present study. The other fatty acids were identified as palmitic (C16:0), linoleic (C18:2n6) and stearic (C18:0) acids in mass fractions of 19.0, 17.5 and $10.3 \%$, respectively (Table 3 ), and these results are in agreement with other studies performed with $Y$. lipolytica grown on glycerol (16). In general, differences in fatty acid profiles seem to result not from culture type, but from substrate type. For example, when glycerol was used as a carbon source by Y. lipolytica UFLA CM-Y9.4, stearic (C18:0) and palmitic (C16:0) acids were predominant in the mass fractions of 87.64 and $74.67 \%$, respectively (36). In turn, using industrial fats in the process with yeast resulted in a different total fatty acid composition, which was characterised by a high concentration of cellular stearic acid (37).

\section{Conclusions}

A growing interest is observed today in the management of glycerol, which seems to be an efficient substrate for erythritol production. One possible application of glycerol shown in this work is efficient production of erythritol using Yarrowia lipolytica MK1 strain in a chemostat culture. The biosynthesis of erythritol in such a system is of high selectivity with low concentrations of by-products. Moreover, the strain preserves its high stability throughout the long-lasting continuous chemostat process. The chemical composition of the biomass was analysed. The mass fractions of lysine and threonine in the biomass protein amino acid profile were higher than those required by the $\mathrm{FAO} / \mathrm{WHO}$ for fodder yeast.

\section{Acknowledgements}

This work was financed by the Ministry of Sciences and Higher Education of Poland and the European Union under Project No. POIG 01.01.02-00-074/09 entitled 'Bioconversion of glycerol into polyols and dicarboxylic acids'.

\section{References}

1. Munro IC, Berndt WO, Borzelleca JF, Flamm G, Lynch BS, Kennepohl E, et al. Erythritol: an interpretive summary of biochemical, metabolic, toxicological and clinical data. Food Chem Toxicol. 1998;36:1139-74. http://dx.doi.org/10.1016/S0278-6915(98)00091-X

2. de Cock P, Bechert CL. Erythritol. Functionality in noncaloric functional beverages. Pure Appl Chem. 2002;74:1281-9. http://dx.doi.org/10.1351/pac200274071281

3. Moon HJ, Jeya M, Kim IW, Lee JK. Biotechnological production of erythritol and its applications. Appl Microbiol Biotechnol. 2010;86:1017-25. http://dx.doi.org/10.1007/s00253-010-2496-4

4. Lin SJ, Wena CY, Wang PM, Huang JC, Wei CL, Chang JW, Chun WS. High-level production of erythritol by mutants of osmophilic Moniliella sp. Process Biochem. 2010;45:973-9. http://dx.doi.org/10.1016/j.procbio.2010.03.003

5. Park J, Seo B, Kim J, Park Y. Production of erythritol in fedbatch cultures of Trichosporon sp. J Gen Appl Microbiol. 1998; 86:577-80. http://dx.doi.org/10.1016/S0922-338X(99)80010-5

6. Ishizuka H, Wako K, Kasumi T, Sasaki T. Breeding of a mutant of Aureobasidium sp. with high erythritol production. J Ferment Bioeng. 1989;68:310-4. http://dx.doi.org/10.1016/0922-338X(89)90003-2

7. Oh DK, Cho CH, Lee JK, Kim SY. Increased erythritol production in fed-batch cultures of Torula sp. by controlling glucose concentration. J Ind Microbiol Biotechnol. 2001;26:24852.

8. Jeya M, Lee KM, Tiwari MK, Kim JS, Gunasekaran P, Kim S. Isolation of a novel high erythritol-producing Pseudozyma tsukubaensis and scale-up of erythritol fermentation to industrial level. Appl Microbiol Biotechnol. 2009;83:225-31. http://dx.doi.org/10.1007/s00253-009-1871-5

9. Rymowicz W, Rywińska A, Marcinkiewicz M. High-yield production of erythritol from raw glycerol in fed-batch cultures of Yarrowia lipolytica. Biotechnol Lett. 2009; 31:377-80. http://dx.doi.org/10.1007/s10529-008-9884-1

10. Tomaszewska L, Rywińska A, Gładkowski W. Production of erythritol and mannitol by Yarrowia lipolytica yeast in media containing glycerol. J Ind Microbiol Biotechnol. 2012;39: 1333-43. http://dx.doi.org/10.1007/s10295-012-1145-6

11. Rywińska A, Juszczyk P, Wojtatowicz M, Robak M, Lazar Z, Tomaszewska L, Rymowicz W. Glycerol as a promising substrate for Yarrowia lipolytica biotechnological applications. Biomass Bioenerg. 2013;48:148-66. http://dx.doi.org/10.1016/j.biombioe.2012.11.021

12. Rywińska A, Marcinkiewicz M, Cibis E, Rymowicz W. Optimization of medium composition for erythritol production from glycerol by Yarrowia lipolytica using response surface methodology. Prep Biochem Biotech. 2015;45:515-29. http://dx.doi.org/10.1080/10826068.2014.940966

13. Tomaszewska L, Rymowicz W, Rywińska A. Mineral supplementation increases erythrose reductase activity in erythritol biosynthesis from glycerol by Yarrowia lipolytica. Appl Biochem Biotechnol. 2014;172:3069-78. http://dx.doi.org/10.1007/s12010-014-0745-1

14. Tomaszewska-Hetman L, Rywińska A. Erythritol biosynthesis from glycerol by Yarrowia lipolytica yeast: effect of osmotic pressure. Chem Pap. 2016;70:272-83. http://dx.doi.org/10.1515/chempap-2015-0201

15. Tomaszewska L, Rywińska A, Gładkowski W. Production of erythritol and mannitol by Yarrowia lipolytica yeast in media containing glycerol. J Ind Microbiol. Biotechnol. 2012;39: 1333-43. http://dx.doi.org/10.1007/s10295-012-1145-6

16. Papanikolaou S, Aggelis G. Lipid production by Yarrowia lipolytica growing on industrial glycerol in a single-stage con- 
tinuous culture. Bioresour Technol. 2002; 82:43-9. http://dx.doi.org/10.1016/S0960-8524(01)00149-3

17. Temudo MF, Poldermans R, Kleerebezem R, van Loosdrecht MCM. Glycerol fermentation by (open) mixed cultures: a chemostat study. Biotechnol Bioeng. 2008;100:1088-98. http://dx.doi.org/10.1002/bit.21857

18. Moon HJ, Jeya M, Kim IW, Lee JK. Biotechnological production of erythritol and its applications. Appl Microbiol Biotechnol. 2010; 86:1017-25. http://dx.doi.org/10.1007/s00253-010-2496-4

19. Mirończuk MA, Dobrowolski A, Rakicka M, Rywińska A, Rymowicz W. Newly isolated mutant of Yarrowia lipolytica MK1 as a proper host for efficient erythritol biosynthesis from glycerol. Process Biochem. 2014;50:61-8. http://dx.doi.org/10.1016/j.procbio.2014.10.020

20. Rywińska A, Tomaszewska L, Rymowicz W. Erythritol biosynthesis by Yarrowia lipolytica yeast under various culture conditions. Afr J Microbiol Res. 2013;7:3511-6. http://dx.doi.org/10.5897/AJMR12.2272

21. Manirakiza P, Covaci A, Schepens P. Comparative study on total lipid determination using Soxhlet, Roese-Gottlieb, Bligh \& Dyer, and modified Bligh \& Dyer extraction methods. J Food Compos Anal. 2001;14:93-100. http://dx.doi.org/10.1006/jfca.2000.0972

22. Ackman RG. Remarks on official methods employing boron trifluoride in the preparation of methyl esters of the fatty acids of fish oils. J Am Oil Chem Soc. 1998;75:541-5.

23. Kita A, Lisińska G, Gołubowska G. The effect of oils and frying temperatures on the texture and fat content of potato crisps. Food Chem. 2007;102:1-5.

http://dx.doi.org/10.1016/j.foodchem.2005.08.038

24. Kjeldahl J. New method for the determination of nitrogen in organic substances. Zeitschrift $\mathrm{f}$ anal Chemie. 1883;22:36683. http://dx.doi.org/10.1007/BF01338151

25. Saldanha AJ, Brauer MJ, Botstein D. Nutritional homeostasis in batch and steady-state culture of yeast. Mol Biol Cell. 2004;15:4089-104. http://dx.doi.org/10.1091/mbc.E04-04-0306

26. Yang SW, Park JB, Han NH, Ryu, YW, Seo JH. Production of erythritol from glucose by an osmophilic mutant of Candida magnolia. Biotechnol Lett. 1999;21:887-90. http://dx.doi.org/10.1023/A:1005566420982

27. Boer VM, de Winde JH, Pronk JT, Piper MD. The genomewide transcriptional responses of Saccharomyces cerevisiae grown on glucose in aerobic chemostat cultures limited for carbon, nitrogen, phosphorus, or sulfur. J Biol Chem. 2003;
278:3265-74.

http://dx.doi.org/10.1074/jbc.M209759200

28. Hoskisson PA, Hobbs G. Continuous culture - making a comeback? Microbiology. 2005;151:3153-9. http://dx.doi.org/10.1099/mic.0.27924-0

29. Rakicka M, Lazar Z, Dulermo T, Fickers P, Nicaud JM. Lipid production by oleaginous yeast Yarrowia lipolytica from industrial by-products under different culture conditions. Biotechnol Biofuels. 2015;8:104.

http://dx.doi.org/10.1186/s13068-015-0286-z

30. Kohl ES, Lee TH, Lee DY, Kim HJ, Ryu YW, Seo JH. Scale-up of erythritol production by an osmophilic mutant of Candida magnoliae. Biotechnol Lett. 2003;25:2103-5. http://dx.doi.org/10.1023/B:BILE.0000007076.64338.ce

31. Davies RJ. Scale up of yeast oil technology. In: Ratledge C, Kyle DJ, editors. Industrial application of single cell oil. Champaign, IL, USA: AOCS Press; 1992. pp. 196-218.

32. Makri A, Fakas S, Aggelis G. Metabolic activities of biotechnological interest in Yarrowia lipolytica grown on glycerol in repeated batch cultures. Bioresour Technol. 2010;101: 2351-8. http://dx.doi.org/10.1016/j.biortech.2009.11.024

33. Bellou S, Makri A, Triantaphyllidou IE, Papanikolaou S, Aggelis G. Morphological and metabolic shifts of Yarrowia lipolytica induced by the alteration of the dissolved oxygen concentration in the growth environment. Microbiology. 2014; 160:807-17. http://dx.doi.org/10.1099/mic.0.074302-0

34. Juszczyk P, Tomaszewska L, Kita A, Rymowicz W. Biomass production by novel strains of Yarrowia lipolytica using raw glycerol, derived from biodiesel production. Bioresour Technol. 2013;137:124-31. http://dx.doi.org/10.1016/j.biortech.2013.03.010

35. Juszczyk P, Rymowicz W. Characterization of microbial biomass production from glycerin waste by various yeast strains. In: Aggelis G, editor. Microbial conversions of raw glycerol. New York, NY, USA: Nova Science Publishers; 2009. pp. 125-35.

36. Souza KS, Schwan RF, Dias DR. Lipid and citric acid production by wild yeasts grown in glycerol. J Microbiol Biotechnol. 2014;24:497-506. http://dx.doi.org/jmb.1310.10084

37. Papanikolaou S, Chevalot I, Komaitis M, Aggelis G, Marc I. Kinetic profile of the cellular lipid composition in an oleaginous Yarrowia lipolytica capable of producing a cocoa butter substitute from industrial fats. Antonie van Leeuwenhoek. 2001;80:215-4.

http://dx.doi.org/10.1023/A:1013083211405 